\title{
A novel Venturi system to generate high flow with titratable $\mathrm{FiO}_{2}$
}

\author{
Andrea Coppadoro ${ }^{1}$, Giacomo Bellani ${ }^{1,2}$ \\ ${ }^{1}$ ASST Monza, San Gerardo Hospital, Monza - Italy \\ ${ }^{2}$ Department of Medicine and Surgery, University of Milan-Bicocca, Monza - Italy
}

\begin{abstract}
Venturi-based flow generators are commonly used for noninvasive continuous positive airway pressure (CPAP) of high-flow nasal oxygen (HFNO). The system is simple and allows to increase the total flow while decreasing the $\mathrm{FiO}_{2}$ starting from a single oxygen source.

In this report we describe the characteristics and performance of a novel Venturi system (EasyVEE, Levate, BG, Italy), which allows to vary the size of the port through which ambient air is entrained, hence allowing a continuous modulation of $\mathrm{FiO}_{2}$.

The system allowed to modify $\mathrm{FiO}_{2}$ continuously between $35 \%$ and $80 \%$ and, consequently, a $1.5-$ to 4.5 -fold increase of the total flow rate. A minimal decrease in entrainment performance was observed for positive endexpiratory pressure levels above $12.5 \mathrm{cmH}_{2} \mathrm{O}$.

EasyVEE system appears to be a simple, flexible, and reliable solution to generate continuous flow for noninvasive respiratory support interfaces.
\end{abstract}

Keywords: CPAP, Noninvasive ventilation, Acute Respiratory Failure, Oxygen

\section{Background and rationale}

Noninvasive ventilatory support, based on free-flow continuous positive airway pressure (CPAP) delivered by helmet or face mask or high-flow nasal oxygen (HFNO), is increasingly used to treat patients with acute respiratory failure (1). During the recent Coronavirus-2019 (COVID-19) pandemic, the use of free-flow system massively spread also outside the intensive care units (2-5). The main advantage of free-flow systems is that an active mechanical ventilator is not required; a flow generator connected to the oxygen pipe or tank can feed a helmet or a face mask to provide CPAP through a positive end-expiratory pressure (PEEP) valve (6), or to nasal cannulas to provide HFNO (7). Flow generators can be either turbine-based or Venturi-based systems.

Venturi systems are based on the principle that a highpressure gas (typically oxygen at $4 \mathrm{~atm}$ ) is delivered through

Received: May 31, 2021

Accepted: September 7, 2021

Published online: October 13, 2021

Corresponding author

Giacomo Bellani

University of Milan-Bicocca

Department of Medicine and Surgery

Via Cadore 48, Monza (MB) - Italy

giacomo.bellani1@unimib.it a small-bore nozzle, reaching a very high speed. Due to Bernoulli's law, once the high-speed gas moves into a larger conduit, it generates a decrease of the lateral pressure, which becomes subatmospheric and entrains another gas (air) from the external atmosphere. In this way, starting from a pure flow of oxygen $\left(Q_{02}\right)$, it is possible to achieve a much higher flow of a mixture of gas $\left(Q_{\text {tot }}\right)$, at a variable $\mathrm{FiO}_{2}$. For each Venturi system, it is hence possible to calculate the flow of gas entrained $\left(Q_{\text {entr }}\right)$ for a given $Q_{\mathrm{O} 2}$, where the ratio $R_{\text {vent }}=\frac{Q_{\text {entr }}}{Q_{\mathrm{O}_{2}}}$. For example, $R_{\text {vent }}=3$ indicates that for each $1 \mathrm{~L} / \mathrm{min}$ of oxygen flowing through the nozzle, three additional liters/minute of gas is entrained, resulting in a total flow of $4 \mathrm{~L} / \mathrm{min}$. The final flow $\left(Q_{\text {tot }}\right)$ depends on $Q_{02}$ and $R_{\text {vent }}$ according to the following formula:

$$
Q_{\mathrm{tot}}=Q_{\mathrm{entr}}+Q_{\mathrm{O} 2}=Q_{\mathrm{O} 2}+Q_{\mathrm{O} 2} * R_{\mathrm{vent}}
$$

The $\mathrm{FiO}_{2}$ of $Q_{\text {tot }}$ (if the gas entrained is air) equals

$$
\mathrm{FiO}_{2}=\frac{\left(Q_{\text {entr }} * 0.21\right)+Q_{02}}{Q_{\text {tot }}}
$$

which, combined with Equation [1] and simplified becomes:

$$
\mathrm{FiO}_{2}=\frac{1+\left(R_{\text {vent }} * 0.21\right)}{1+R_{\text {vent }}}
$$


Hence, if $R_{\text {vent }}$ does not change, varying $Q_{02}$ to the nozzle will not vary the $\mathrm{FiO}_{2}$ of $Q_{\text {tot' }}$ but only $Q_{\text {tot }}$ itself.

$R_{\text {vent }}$ depends mainly not only on the diameter and shape of the nozzle orifice but also on the pressure downstream, as positive pressure decreases the entrainment ability of Venturi.

From a clinical standpoint, this is relevant, since when delivering free-flow CPAP using a Venturi system to generate the flow, any PEEP increase will cause an $\mathrm{FiO}_{2}$ increase, which might be misinterpreted as a patient's response to PEEP. Finally $R_{\text {vent }}$ tends to decrease for low $Q_{02}$, due to the loss of entrainment at lower gas speeds. A typical behavior of a Venturi system is displayed in Figure 1.

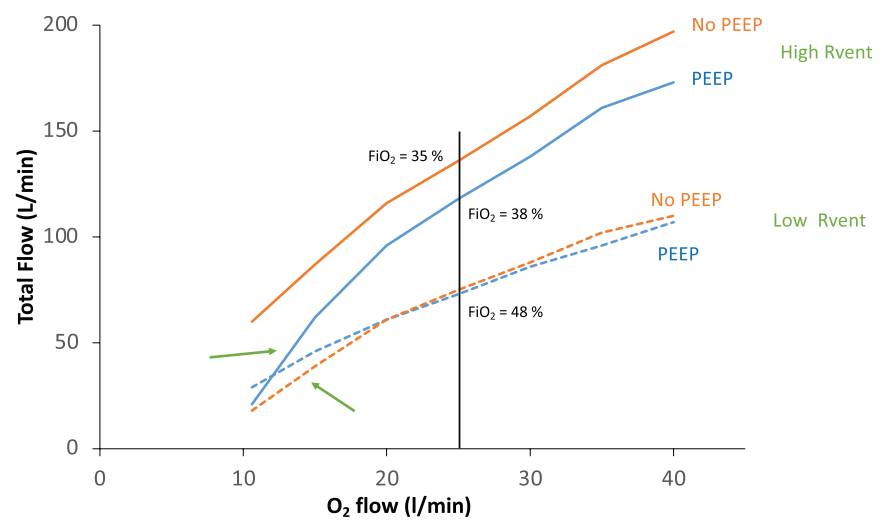

Fig. 1 - Characteristic behavior of Venturi systems with higher or lower entrainment of ambient air (expressed as the ratio between initial oxygen flow and entrained air, $\left.R_{\text {vent }}\right)$. For the same $\mathrm{O}_{2}$ flow the Venturi with a higher entrainment will lead to a greater total flow, with lower $\mathrm{FiO}_{2}$ (due to the greater amount of air in the final mixture) and vice versa. Notice that a PEEP increase may determine a decrease of the performance of the same Venturi (as the positive pressure decreases the entrainment capabilities). Finally, in the low range of $\mathrm{O}_{2}$ flow (green arrow), the $R_{\text {vent }}$ of the Venturi can drop, leading to low total flow rates and higher $\mathrm{FiO}_{2}$.

\section{Description of the system}

We herein describe and characterize a novel Venturi system (EasyVee flowmeter, Levate, Bergamo, Italy), coupled with a variable area oxygen flowmeter, connected to a high-pressure (4 bar) $\mathrm{O}_{2}$ source. The Venturi nozzle (with a diameter of $1.1 \mathrm{~mm}$ ) is characterized by a nominal $R_{\text {vent }}$ of approximately 4.5 when operating without downstream pressure. A novel solution is that the size of the aspiration port (open to ambient air) can be modulated, by means of a nonius, from full opening to complete closure (Fig. 2). The excursion progresses continuously, but six precalibrated marks are put in order to facilitate $Q_{\text {entr }}$ (and hence $\mathrm{FiO}_{2}$ ) titration with the use of a table or an app.

Because of the size of the nozzle, the maximum achievable flow from a standard 4-bar oxygen wall port equals 38-40 L/min, even if the flow meter is opened to full scale. Therefore, when the nonius is completely closed to deliver pure oxygen $\left(\mathrm{FiO}_{2} 100 \%\right)$, the total flow might be inadequate
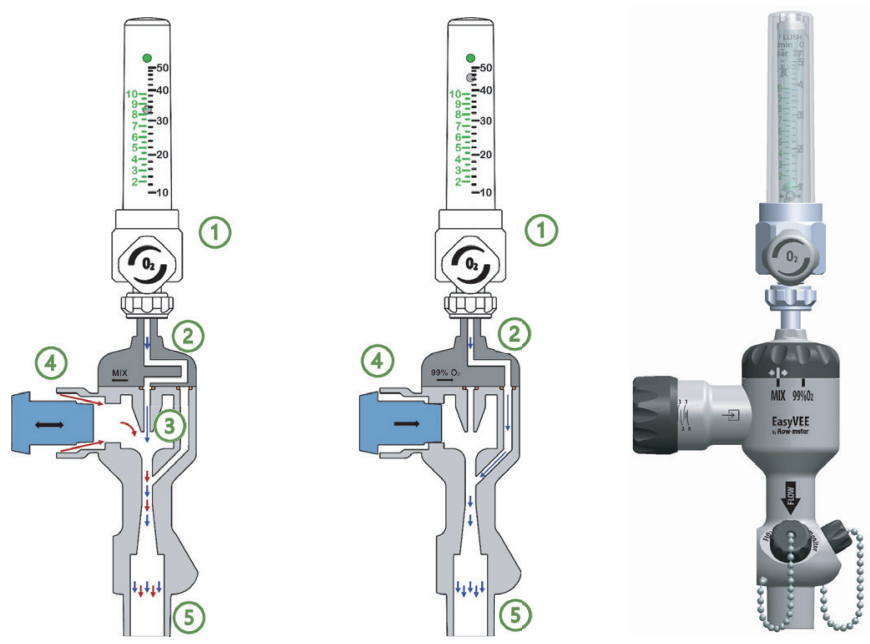

Fig. 2 - Representation of the novel Venturi. Panel A: The oxygen (blue) flow delivered by a variable surface flowmeter (1) is directed (2) through the small nozzle (3) where the high speed and subsequent enlargement of the section causes an entrainment of air from the ambient through a nonius (4), whose bore can be modulated, varying the final (5) $\mathrm{FiO} 2$ and total flow. Panel B: In the case of pure oxygen delivery, the Venturi nozzle is bypassed by a switch (2) and flow follows an auxiliary larger-bore path. Panel C: Image of the device.

to provide noninvasive CPAP support; a novel solution is the presence of a switch to bypass the Venturi nozzle, achieving up to $70 \mathrm{~L} / \mathrm{min}$ oxygen flows.

\section{Methods}

In this bench study we evaluated the performance of the novel Venturi system, in terms of total flow generated and $\mathrm{FiO}_{2}$ for different $Q_{\mathrm{O}_{2}}$, nonius position, and PEEP loads, to simulate different clinical scenarios. Total flow and $\mathrm{FiO}_{2}$ were measured by VT Plus HF (Fluke Biomedical, USA). $\mathrm{FiO}_{2}$ was measured additionally by PICK-O2 (Medizintechnik Juergen K. Kranz $\mathrm{GmbH}$ ) and values were averaged to obtain the measured $\mathrm{FiO}_{2}\left(\mathrm{FiO}_{2, \text { meas }}\right)$. Theoretical $\mathrm{FiO}_{2}\left(\mathrm{FiO}_{2, \mathrm{th}}\right)$ was calculated as:

$$
\mathrm{FiO}_{2, \mathrm{th}}=\frac{Q_{02}+\left(\dot{Q}_{\mathrm{tot}}-Q_{02}\right) \cdot 0.21}{Q_{\mathrm{tot}}}
$$

and compared with $\mathrm{FiO}_{2 \text {,meas }}$ to verify internal data consistency.

For each condition $R_{\text {vent }}$ was calculated as:

$$
R_{\text {vent }}=\frac{\left(\dot{Q}_{\mathrm{tot}}-Q_{02}\right)}{Q_{\mathrm{tot}}}
$$

\section{Results}

(Fig. 3). 


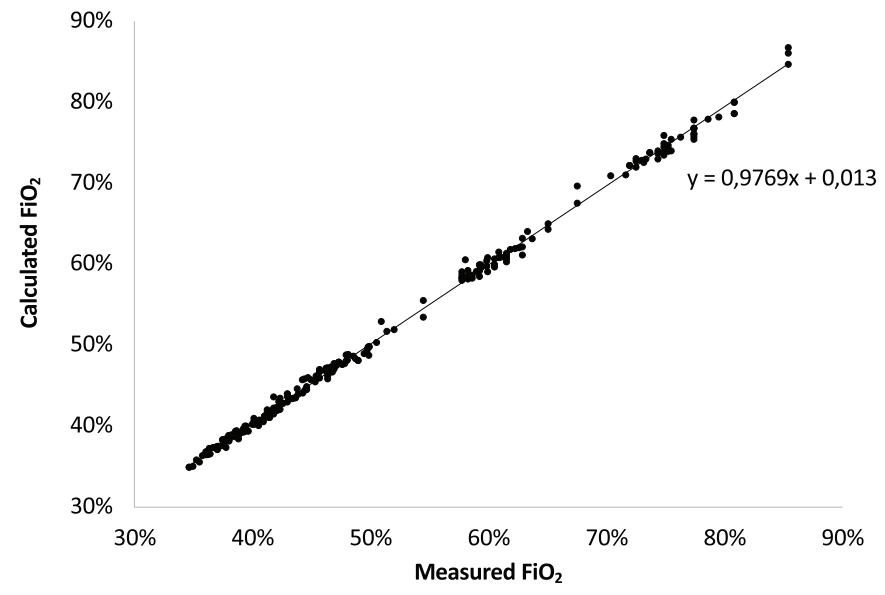

Fig. 3 - Tight correlation between the measured and theoretical $\mathrm{FiO}_{2}$ of the final gas flow, with a slope very close to identity, reinforcing the internal consistency of the data.

Figure 4 shows the performance of the novel Venturi system for different $Q_{\mathrm{O} 2}$ and position of the nonius, for a PEEP value of $7.5 \mathrm{cmH}_{2} \mathrm{O}$. As expected, progressively closing the nonius leads to a decrease of the air entrained by the Venturi (decreasing $R_{\text {vent }}$ ) and hence $Q_{\text {tot }}$ (upper panel), allowing to achieve higher $\mathrm{FiO}_{2}$ (lower panel), in the range between $35 \%$ and $80 \%$.

As shown in Figure 5, the performance of the novel Venturi system, measured as capacity to entrain air $\left(R_{\text {vent }}\right)$, remained rather stable over a wide range of PEEP, showing a sensible impact only for PEEP levels above $12.5 \mathrm{cmH}_{2} \mathrm{O}$, particularly if a low $Q_{02}$ is used (upper panel).

\section{Discussion}

In this report we described the pneumatic performance of the EasyVEE system, a Venturi flow generator equipped with an adjustable air entraining port and a single extendedrange flowmeter. The novel system was very flexible, in generating high-flow gas mixture, with a simple control to titrate $\mathrm{FiO}_{2}$ and a constant performance over a wide range of PEEP and $Q_{\mathrm{O} 2}$.

As mentioned, an adequate flow of fresh gas is necessary in order to efficiently deliver CPAP or HFNO. This is often achieved by Venturi systems, which drop the $\mathrm{FiO}_{2}$ proportionally to their efficiency in gas entrainment. Standard Venturi systems are typically built with a fixed (not adjustable) port for air entrainment; therefore, a second flowmeter is needed to increase $\mathrm{FiO}_{2}$ by addition of oxygen to the gas mixture generated by the Venturi. At variance from these, the EasyVEE foresees a progressive reduction of the air opening, so that the net result is an adjustable $R_{\text {vent }}$ and an increase in $\mathrm{FiO}_{2}$.

Another crucial point of the Venturi systems is the loss of performance for increasing back pressures, typically due to PEEP increase. In this respect, the EasyVEE maintains a relatively constant performance over a wide range of PEEP levels, albeit the use of a direct $\mathrm{FiO}_{2}$ measure or custom tables for the device is recommended to determine the exact $\mathrm{FiO}_{2}$ after any therapeutic adjustment.

In conclusion the EasyVEE system appears to be a simple, flexible, and reliable solution to generate continuous flow for noninvasive respiratory support interfaces.
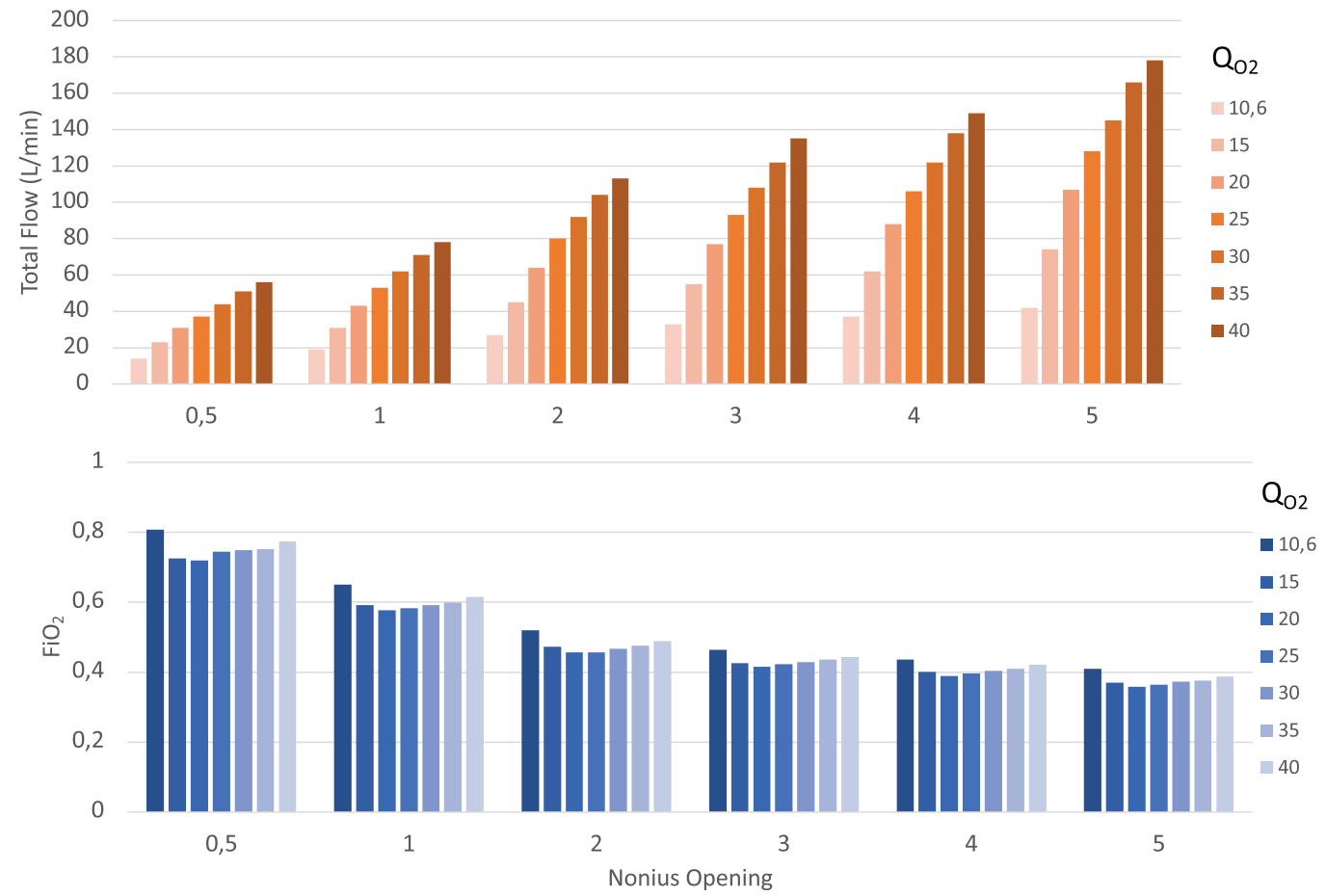

Fig. 4 - Total flow (upper panel) generated by the novel Venturi system depending on the $\mathrm{O}_{2}$ flow $\left(Q_{\mathrm{O} 2}\right)$ and nonius opening. As expected (lower panel) $\mathrm{FiO}_{2}$ decreases for progressive openings of the nonius, allowing a fine titration between $35 \%$ and $80 \%$. $\mathrm{FiO}_{2}$ does not vary with $Q_{02}$, allowing a separate titration of total flow and $\mathrm{FiO}_{2}$. 


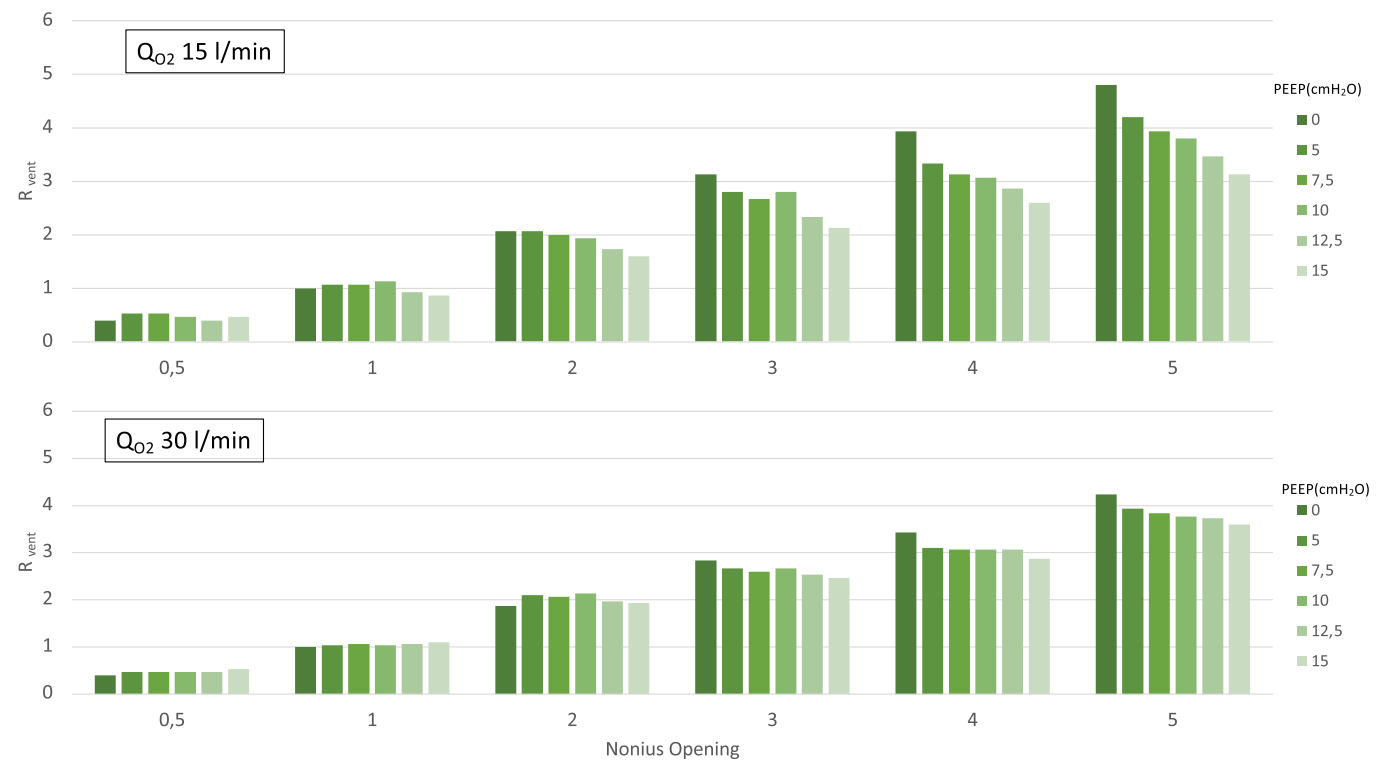

Fig. 5 - Impact of positive endexpiratory pressure on the ability of Venturi to entrain air from the external environment. $R_{\text {vent }}$ expresses the ratio between the $\mathrm{O}_{2}$ flow $\left(Q_{02}\right)$ and the flow of air entrained. For example, an $R_{\text {vent }}=2$ indicates that a $Q_{\mathrm{O} 2}$ of $20 \mathrm{~L} / \mathrm{min}$ will entrain $40 \mathrm{~L} / \mathrm{min}$ from the environment, generating a total flow $\left(Q_{\text {tot }}\right)$ of $60 \mathrm{~L} / \mathrm{min}$. In the novel system $R_{\text {vent }}$ can be easily titrated acting on the nonius, but, conveniently, the value is stable irrespective of $Q_{02}$ and PEEP (unless for extreme values).

\section{Disclosures}

Conflict of interest: Both authors are coinventors on patents and receive consultancy fees from Flow-Meter SPA (Levate, BG, Italy) for a matter related to the topic of the article.

Financial support: None.

\section{References}

1. Ferreyro BL, Angriman F, Munshi L, et al. Association of noninvasive oxygenation strategies with all-cause mortality in adults with acute hypoxemic respiratory failure: a systematic review and meta-analysis. JAMA. 2020;324(1):57-67. CrossRef PubMed

2. Bellani G, Grasselli G, Cecconi M, et al. Noninvasive ventilatory support of patients with COVID-19 outside the intensive care units (WARd-COVID). Ann Am Thorac Soc. 2021;18(6):10201026. CrossRef PubMed
3. Coppadoro A, Zago E, Pavan F, et al. The use of head helmets to deliver noninvasive ventilatory support: a comprehensive review of technical aspects and clinical findings. Crit Care. 2021;25(1):327. CrossRef PubMed

4. Alharthy A, Faqihi F, Noor A, et al. Helmet continuous positive airway pressure in the treatment of COVID-19 patients with acute respiratory failure could be an effective strategy: a feasibility study. J Epidemiol Glob Health. 2020;10(3):201-203. CrossRef PubMed

5. Aliberti S, Radovanovic D, Billi F, et al. Helmet CPAP treatment in patients with COVID-19 pneumonia: a multicentre cohort study. Eur Respir J. 2020;56(4):56. CrossRef PubMed

6. Brusasco C, Corradi F, De Ferrari A, Ball L, Kacmarek RM, Pelosi P. CPAP devices for emergency prehospital use: a bench study. Respir Care. 2015;60(12):1777-1785. CrossRef PubMed

7. Garofalo E, Bruni A, Pelaia C, et al. Evaluation of a new interface combining high-flow nasal cannula and CPAP. Respir Care. 2019;64(10):1231-1239. CrossRef PubMed 